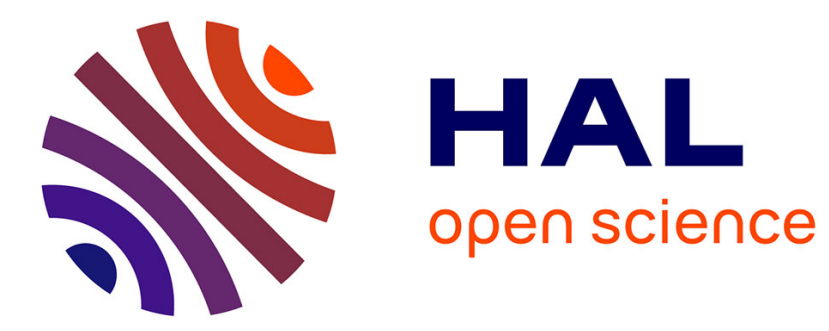

\title{
Impact of planarization sheet addition on full wafer printing uniformity
}

\author{
Tanguy Lévéder, Stéfan Landis, Laurent Davoust, Nicolas Chaix
}

\section{To cite this version:}

Tanguy Lévéder, Stéfan Landis, Laurent Davoust, Nicolas Chaix. Impact of planarization sheet addition on full wafer printing uniformity. MRS Online Proceedings Library, 2007, Symposium O - Nanostructured and Patterned Materials for Information Storage, 961, pp.0961-O02-06. 10.1557/PROC0961-O02-06 . hal-00266800

\section{HAL Id: hal-00266800 \\ https://hal.science/hal-00266800}

Submitted on 10 Feb 2020

HAL is a multi-disciplinary open access archive for the deposit and dissemination of scientific research documents, whether they are published or not. The documents may come from teaching and research institutions in France or abroad, or from public or private research centers.
L'archive ouverte pluridisciplinaire HAL, est destinée au dépôt et à la diffusion de documents scientifiques de niveau recherche, publiés ou non, émanant des établissements d'enseignement et de recherche français ou étrangers, des laboratoires publics ou privés. 


\title{
Impact of Planarization Sheet Addition on Full Wafer Printing Uniformity
}

Tanguy Leveder ${ }^{1}$, Stefan Landis ${ }^{1}$, Laurent Davoust ${ }^{2}$, and Nicolas Chaix ${ }^{3}$

${ }^{1}$ CEAlLETI - Minatec, 17, rue des martyrs, Grenoble, France

${ }^{2}$ ENSHMG-LEGI, Grenoble, France

${ }^{3}$ CNRSILTM, 17, rue des martyrs, Grenoble, France

\begin{abstract}
Uniformity of nanoimprint lithography has been quantitatively studied through the ability to replicate regular lines arrays by wafer-to-wafer imprint. Two statistic coefficients have been defined in order to quantify the local uniformity and the ability to identically imprint two similar areas respectively. Those coefficients enable to compare different imprint profiles in terms of uniformity and to point out the efficiency of soft layers insertion into the imprint stack.
\end{abstract}

\section{Introduction}

The International Technology Roadmap for Semiconductor (ITRS) trends predict constant downsizing of the features and improvement of electrical properties of nanoscale devices. Altough lower wavelength of optical sources or immersion techniques are proposed to improve capabilities of conventional projection lithographies, other approaches have been proposed for Next Generation Lithographies (NGL). Nanoimprint lithographies are now emerging as the longawaited disruptive technologies [1].

Many aspects of nanoimprint lithography, as resolution [2] or throughput [3] have been studied, and the non uniformity of imprinted patterns henceforth appears as an important issue. Non uniformities have been already studied $[4,5,6]$; especially in the case of residual thicknesses remaining in the case of pattern density variation $[4,5]$. Ground-breaking answers like micro dispensing [7] were proposed. However, even in uniform pattern arrays, imprinted depths non uniformities are often observed, though they are more seldom reported [8].

To improve the imprint uniformity and reduce the number of imprinted defects, the Nanoimprint community usually insert soft material layer between the stamp and the applying-force system of the imprint tool (figure 1) leading to a significant improvement of imprints. This paper is a first quantitative analyze of the different imprint configurations (figure 1). In the first section we will see both which parameters are needed to quantify the imprint uniformity, and the experimental set-up. Then we will define two statistic coefficients which are used to quantify the uniformity at the die and at the wafer scale respectively. Finally, impact of soft material layer used into the imprint stack will be reported.
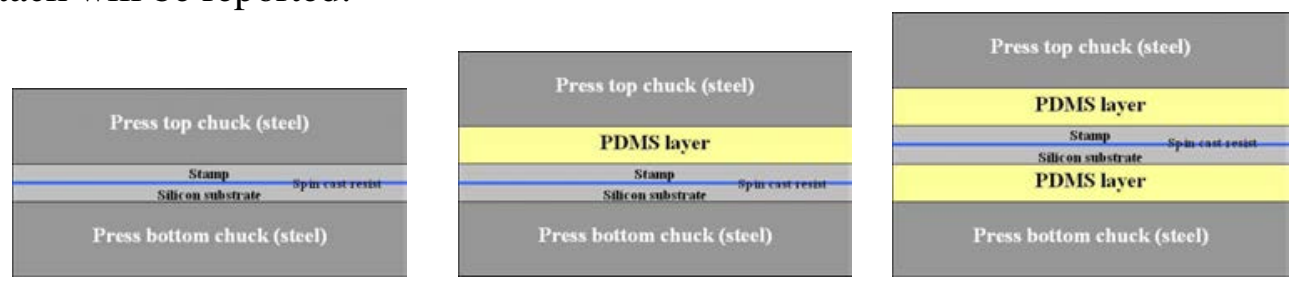

Figure 1: sketch of considered imprint stack. The reference configuration (a) without any soft layer is compared with two stacks including either one (b), or two (c) soft layers. 


\section{Experimental section}

\section{Studied configurations}

In this paper, we will focus on the uniformity of imprinted depths. Figures 2 show why this non uniformity could be distinguished either as a local defect, or as a global one.
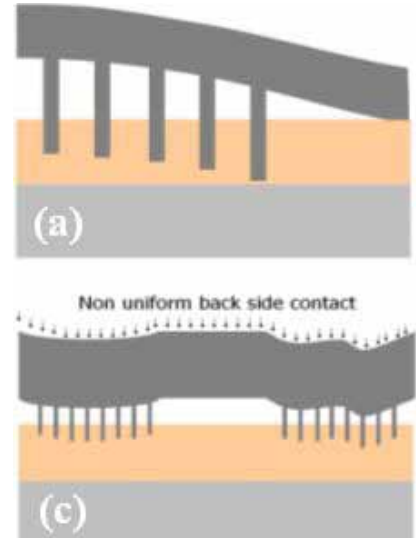
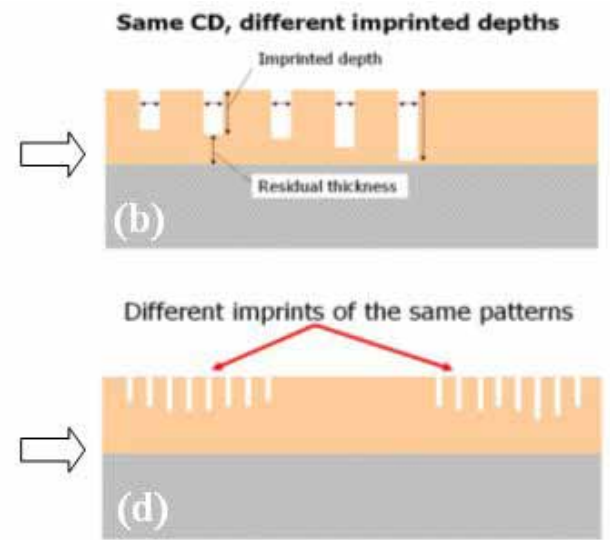

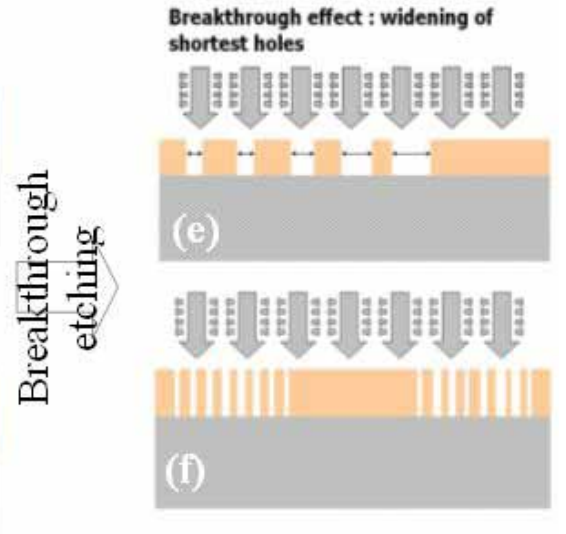

Figure 2: Origin of studied non-uniformity. Influence of imprinted depth on pattern transfer. The first situation leading to non uniform residual layer or imprinted depth could be observed at the transition areas between two patterns with different density. The most widely observed configuration corresponds to the border of a pattern without surrounding features as shown by figure $2 \mathrm{a}[4,5]$. This imprint configuration will lead to a non uniform residual layer distribution in this area as shown in Figure 2b. It is noticeable that this defect occurs even before the complete filling of cavities, since a different pattern density often corresponds to a different imprint velocity. Thus, at any time during the imprint, as well as at the final state when all cavities are filled, the imprinted depths are not uniform.

The second situation which should be considered is the ability to replicate a same pattern at different locations of the wafer. During a wafer-to-wafer imprint, every imprinted die is supposed to be imprint with the same condition of temperature and pressure. Therefore, two identical patterns onto the stamp should give the same residual layer distribution (figure 2c). Nevertheless, due to the stamp and substrate roughness and waviness, local imprint conditions are not uniform (figure 2c), what is leading to dissimilar depth profiles from a die to another (figure $2 \mathrm{~d}$ ). We assume that this non repeatability is due to a non uniform back side pressure, due to a non uniform contact between the stamp and the pressure plate of the press. This defect is absolutely unpredictable, that is why this issue is supposed to be intrinsically due to the defects or combination of defects - of stamp, substrate or press.

This study focuses onto the imprinted depth uniformity. The control of this parameter is critical to control pattern transfer into the underneath layer. Indeed, to remove the residual thickness remaining under the imprinted patterns, a breakthrough etching is usually performed (figure $2 \mathrm{e}$ and $2 \mathrm{f}$ ). The deepest patterns will be opened first. But during the opening of the area with larger residual layer thicknesses, the lateral etching rate of the Reactive Ion Etching (RIE) will widen the edges of the opened patterns [3]. Figure $2 \mathrm{e}$ and $2 \mathrm{f}$ show these pattern size modifications during the breakthrough etching in the two studied cases. 


\section{Experimental conditions, metrology}

To characterize the influence of soft material layers use into the imprint stack (figure 1); a specific stamp has been designed to allow the measurement of residual layer distribution across large imprinted surfaces.

Stamp was designed in order to prevent from any complex polymer flow. Four $4 \mathrm{~mm} \times 4 \mathrm{~mm}$ square line arrays were etched onto a $200 \mathrm{~mm}$ silicon wafer (figure 3 ). The linewidth is $1 \mu \mathrm{m}$ and the pitch is $10 \mu \mathrm{m}$. The linewidth is large enough to enable either profilometer or Atomic Force Microscope (AFM) to measure the bottom of the imprinted grooves. The local non uniformity could be determined on each array border, whereas the global non uniformity could be characterized by imprint profiles comparison between the different arrays.

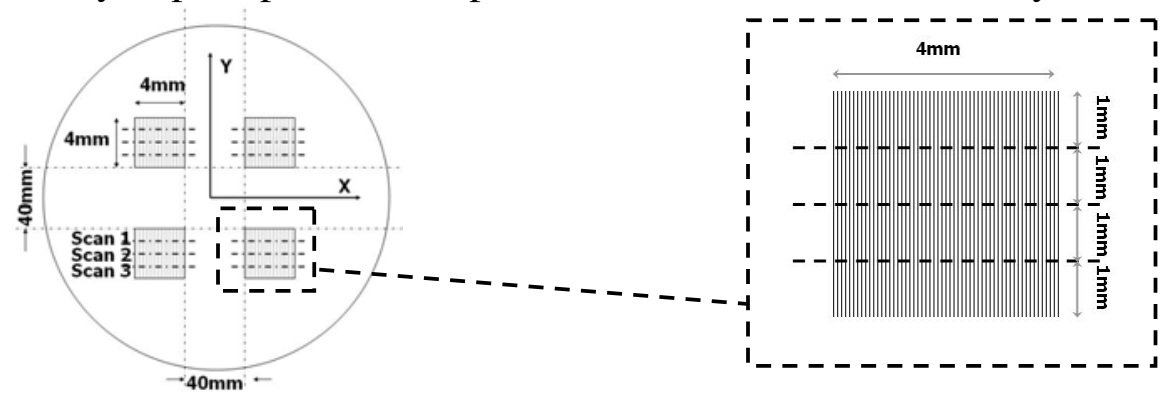

Figure 3: stamp layout. 4 identical gratings. Each die is a $4 x 4 \mathrm{~mm}$ square array on $1 \mu \mathrm{m}$ wide lines with a $10 \mu \mathrm{m}$ period. Silicon lines are $200 \mathrm{~nm}$ high. Measurement sites are displayed with the dotted lines.

The printing processes have been carried out on EVG®520HE system for substrate sizes up to $200 \mathrm{~mm}$ wafers $[5,8]$. The printing process is performed under a $5.10^{-4}$ bar vacuum. Imprints have been carried out into $210 \mathrm{~nm}$ thick mr-I 7020E resist from Micro Resist Technology at $130{ }^{\circ} \mathrm{C}\left(\mathrm{Tg}+70{ }^{\circ} \mathrm{C}\right)$ under $20 \mathrm{kN}$ for $300 \mathrm{~s}$.

The imprinted profiles were measured with a KLA Tencor® HRP340 profilometer. This tool is designed for scan length up to $300 \mathrm{~mm}$. Measurement sites are distributed on every quarter of the die in the $\mathrm{Y}$ direction. So, uniformity of an imprint will be characterized from 12 scans. However, one of the four dies entails a big defect looking like a speck of dust, which prevents from using data of this die. That is why only nine imprinted profiles are considered in this paper.

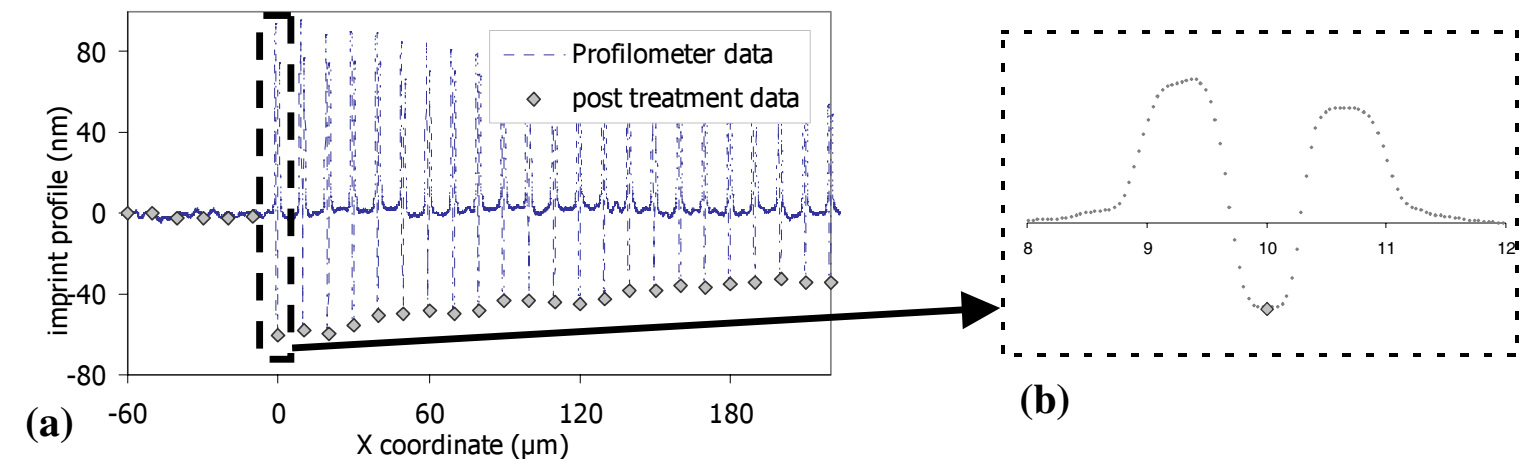

Figure 4: Experimental imprinted resist profile (a) in dotted line. Imprinted depth has been extracted for each line from the whole profile (diamond symbol). Figure 4.b is a magnification of one imprinted resist profile.

As the printed line is $1 \mu \mathrm{m}$ wide, a $20 \mathrm{~nm}$ horizontal scanning resolution has been chosen to get the deepest imprinted point reach by each line of the stamp. Consequently, the experimental data files were composed of more than $2.10^{5}$ measurement points for each scan, analyzed with a home 
made $\mathrm{C}++$ software determining every line depth (figure 4a). The imprinted depths are computed by the difference of level between non imprinted areas and imprinted lines (figure $4 \mathrm{~b}$ ). These depths had been locally confirmed by AFM measurements.

Three stack configurations have been tested as depicted in figures 1. Soft material layers are made of polydimethylsiloxane (PDMS) material, a room-temperature vulcanizing elastomer. The PDMS layers are $4 \mathrm{~mm}$ thick, since thicker layer do not lead to significant improvement of imprint quality.

\section{Results and discussion}

\section{Statistical tools for analysis}

From experimental set up described in part 2.2, we succeed to measure the imprinted depths distribution for each die.

In a first approach, it is interesting to compare on a same chart (Figure 5) results of imprint in the same experimental condition for the different stacks previously described (Figure 1).

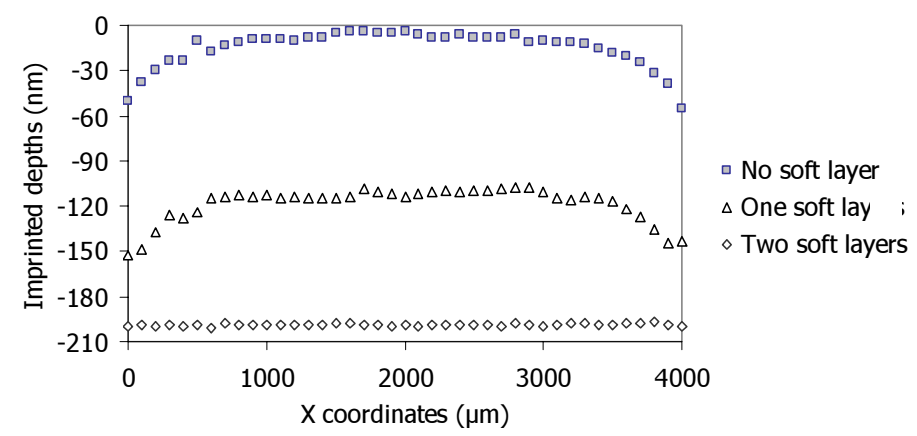

Figure 5: Imprinted depth profile across a whole die for the three configurations considered in this paper: with no soft layer (square symbol), with one soft layer (triangular symbol), and with two soft layers (diamond symbol). Only one tenth of the points are plotted to improve readability.

We can notice that the profile of the configuration with only one layer is clearly deeper than the one without any soft layer, but with similar shapes. It could be due to the homogenous pressure contribution of the soft layer compression. Without any layer, pressure comes only from contact points between silicon stamp and metallic chuck of the press. On the contrary, with one or two soft layers; one or two homogenous pressure contributions are added. It provides either a deeper imprint, or a full filled imprint.

Influence of soft layer is obvious. First, the mean values of the imprinted depths are significantly different whereas imprint conditions were similar (time, temperature and pressure). Then, the ratio of deviation compared with the mean value decreases a lot with the addition of soft layers: from $\pm 30 \mathrm{~nm}$ to $\pm 5 \mathrm{~nm}$ with no soft material layer and two soft material layers respectively. Moreover, we will further consider every profile as a series and analyze those series with tailored statistic tools.

In order to exhibit local and global uniformity, this data should be analyzed in two different ways.

We introduced a dimensionless number which is the ratio between the standard deviation coefficient and the mean value of a profile. We call this number the Local Uniformity Coefficient (LUC) which quantifies dispersion of imprinted depths at a location neighborhood. For a flat profile (all values identical), LUC will be equal to $0 \%$, whereas for a very curved or 
dispersed series, LUC may be larger than $100 \%$ if the standard deviation grows upper than the mean value of the series.

$$
L U C=\frac{1}{\sum X} \cdot \sqrt{n \frac{n\left(\sum X^{2}\right)-\left(\sum X\right)^{2}}{(n-1)}} \text { (1) } \quad G U C=1-\frac{n\left(\sum X Y\right)-\left(\sum X\right)\left(\sum Y\right)}{\sqrt{n \sum X^{2}-\left(\sum X\right)^{2}} \sqrt{n \sum Y^{2}-\left(\sum Y\right)^{2}}}
$$

From another point of view, each series could be compared to other series from the same imprint. By estimating the similarity between different profiles, global uniformity is quantified. To quantify this parameter, we defined a Global Uniformity Coefficient (GUC), a dimensionless number measuring the deviation form a given series to another one (equation 2). This coefficient characterizes similarity between two series and may range from 0 (for identical series) to 1 (for two non correlated series).

\section{Influence of soft layer on uniformity}

From a macroscopic point of view, Figures 6 show how obvious is improvement of imprint uniformity with soft material layers addition.

(a)

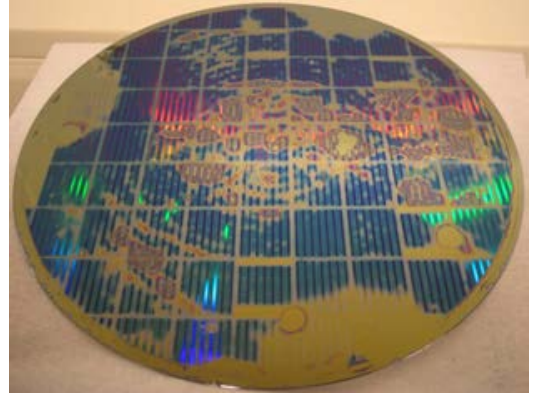

(b)

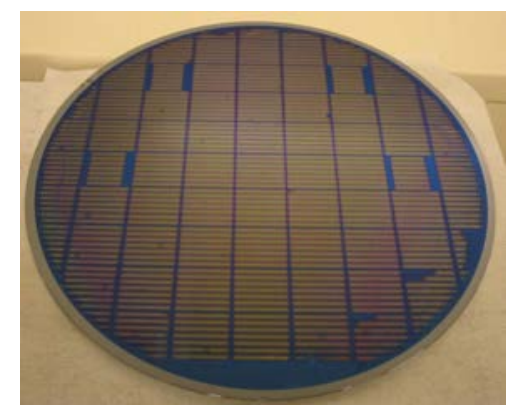

Figure 6: optical picture of the imprinted wafer without (a) or with (b) soft layers.

For a given stack configuration, a reference profile (indexed \#1) is arbitrary fixed. Then, GUC is computed for every predefined die and position on the imprinted wafer (indexed from \#2 to \#9). Therefore, we calculated three curves showing rate of deviation according to a reference for each stack configuration. Figure 7a clearly shows that use of soft layers improves drastically imprint repeatability. The GUC decreases from value larger than $40 \%$ to value smaller than $1 \%$, that is to say a $1 \sigma$-deviation lower than $1 \mathrm{~nm}$ on the studied pattern, for configuration with no and two soft material layers respectively.
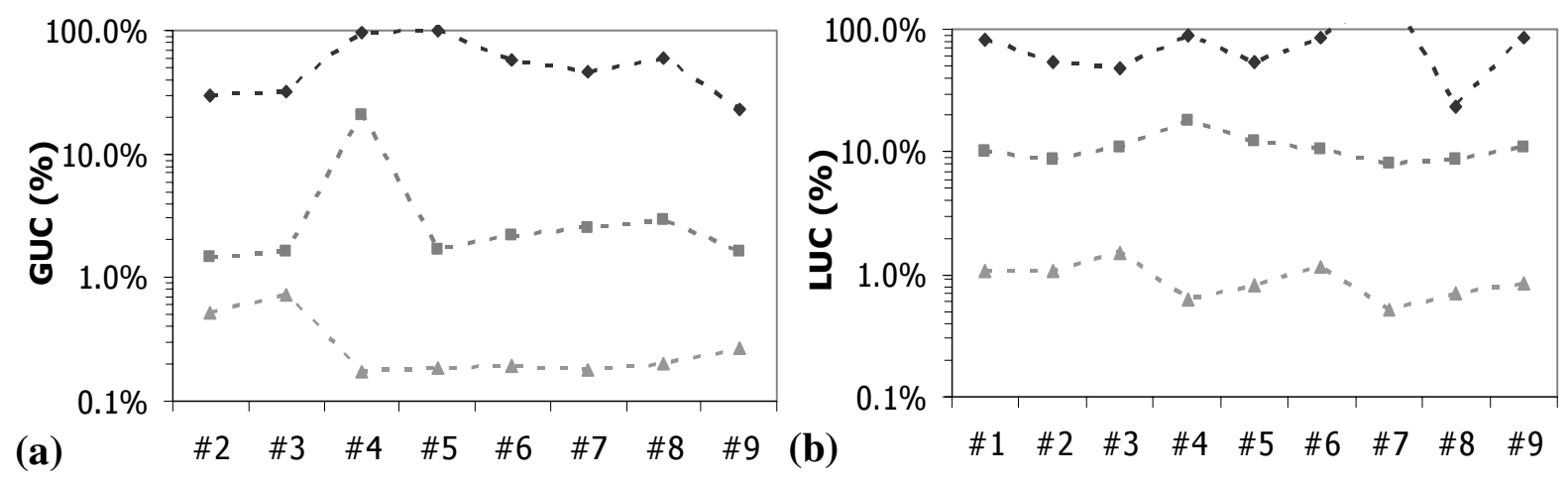

- - - - No layer - - - - One layer

- - - - - Two layers

Figure 7: LUC and GUC distribution for nine scan lines. Imprints have been performed with no soft layer (diamond symbols), one soft layer (square symbols), or two soft layers (triangular symbols). 
Basically, we can consider that inserting one soft material layer improves imprint repeatability of about one decade. In the "no soft layer" case GUC can reach $100 \%$, that is to say that if one of the two series used for the GUC computation is well-imprinted, the other one is very badly imprint or maybe absolutely not. It could also imply that in the areas where first profile is good, the second is worse, and vice versa. But in the "two layers" case, GUC is so low that it indicates a very strong correlation between the two profiles: for every position in the scanned profile, the imprinted depths are similar for all scans.

To characterize local uniformity of imprint process the LUC is computed from the same experimental data that for global uniformity measurement. This time, LUC is an intrinsic parameter of a given profile, so nine values of LUC could be calculated for every stack configuration (Figure 7b). As for the GUC, LUC decreases radically with the introduction of soft material layer in the imprint stack. This reveals a significant flattening of profiles at interface between different density areas, where non uniformity was usually located (Figure 5). Figure 7b shows that in the "no soft layer" case, profile curvature could be at the same level that the mean depth (and even higher for \#7 where the LUC is greater than 100\%). On the contrary, in the "two soft layers" case, the LUC is around 1\%, which is indicated that deviation of such a profile is lower than $2 \mathrm{~nm}$, for an imprinted depth of 200nm.

Even if GUC and LUC present the same trends with the introduction of soft layer, it should be noticed that they imply two radically different behaviors. If the profile curvatures increase with the addition of soft material layers, but became more similar one to each other, GUC would be good and LUC would not. On the contrary, it could be possible that the profiles became very flat, but totally different from a position to the other. In this case GUC would be bad and LUC good. So we are in the very lucky situation where both global and local uniformity are improved. The "two soft layers" case is finally providing a quasi perfect imprint, with less than $10 \mathrm{~nm}$ of residual thickness and imprint depth standard deviation below $1 \%$ from die to die or inside a given die.

\section{Conclusion}

It has been shown that usual intuitive experimental cleverness used in NanoImprint Lithography could be highly pertinent, powerful, and cost effective. By performing quantitative analysis onto imprinted wafers, it has been possible to demonstrate the significant impact of soft material layers onto local pattern replication as well as onto process repeatability. This statistic tools will be necessary for optimizing thickness and softness of soft material layers and further investigations will be performed to improve imprint uniformity in more complex stamp configurations.

\section{References}

1. S.Y. Chou, P.R. Krauss, P.J. Renstrom, Appl. Phys. Lett. 67, 3114(1995).

2. G.Y. Jung, E. Johnston-Halperin, W. Wu, Z. Yu, S.-Y. Wang, W. M. Tong, Z. Li, J. E. Green, B. A. Sheriff, A. Boukai, J. R. Heath, R. S. Williams, Nano Lett. 4, 533(2004).

3. L. Jay Guo, J. Phys. D 37, R123 (2004).

4. N. Bogdanski, M. Wissen, H.-C.Scheer, Proc. SPIE 5835, 282 (2005).

5. D. Fuard, C. Perret, C. Gourgon, P. Schiavone, J. Vac. Sci. Technol. B 23, 3069 (2005).

6. D. P. Mancini, K. A. Gehoski, W. J. Dauksher, K. J. Nordquist, D. J. Resnick, P. Schumaker, Ian McMackin, presented at SPIE Microlithography Conference, 2003.

7. A. Abdo, S. Schuetter, G. Nellis, A. Wei, R. Engelstad, V. Truskett, J. Vac. Sci. Technol. B 22, 3279 (2004).

8. C. Gourgon, C. Perret, G. Micouin, F. Lazzarino, J.-H. Tortai, O. Joubert J. Vac. Sci. Technol. B 21, 98(2003). 